\title{
Black-footed ferret update
}

\section{Robert M. May}

MANY readers will have heard about the black-footed ferret, which used to be found over a fair fraction of North America (eating prairie dogs), then declined to the point where it was suspected of being extinct, and was found again near Meeteetse in Wyoming in 1981. Soon after its discovery, the Meeteetse colony was devastated by an outbreak of canine distemper. By October 1985, this only known colony of ferrets had been reduced to six individuals who - after some controversy - had been taken into captivity by the Wyoming Game and Fish Department, along with six or so individuals remaining in the wild ${ }^{1,2}$. The Blackfooted Ferret Recovery Plan, just published by the US Fish and Wildlife Service ${ }^{1}$,

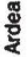

\section{IMAGE UNAVAILABLE FOR COPYRIGHT REASONS}

Optimism for the black-footed ferret?

offers a carefully considered view of how best to manage this threatened ferret population, in both the short and long run.

When I last wrote in News and Views on this topic ${ }^{3}$ early in 1986, a breeding programme was about to start within this captive colony of four females and two males. I took a pessimistic view. Subsequent developments at first were indeed gloomy: only one of the males appeared capable of breeding, and no offspring were produced in the captive-breeding programme during that winter and spring.

In the summer of 1986 , however, five adults and two litters were found in the wild. One male ferret was captured and brought into the breeding population. Opinion continued to harden that the population was at risk of extinction, and that the only sensible action was to capture all the remaining wild animals. In September, most of the remaining wild ferrets were trapped, bringing the captive total to 17 ( 11 females and 6 males); one additional wild male was captured in February $1987^{2.4}$.

The subsequent story is a happy one ${ }^{1}$. Two litters were born in summer 1987, representing the first success at propa- gating this species in captivity. By late 1988, the Wildlife Research and Conservation Education Centre at Sybille, Wyoming, was home to no fewer than 58 ferrets, 17 wild-caught and 41 captivereared. The most immediate aim of the recovery plan $^{1}$ is to build the captive population to around 200 , a goal which should be reached by 1991 . By the year 2010 , it is hoped to have established 10 or more separate populations in the wild, each numbering around 150 ferrets. This number - a total of 1,500 distributed among 10 or so subpopulations - was arrived at in a necessarily tentative way as offering a good chance of self-sustaining persistence in the face of such natural adversities as epidemics of disease and other environmental unpredictabilities ${ }^{5,6}$.

A population of this size would also retain something like 90 per cent of the present genetic diversity in black-footed ferrets $^{6}$, which itself is, however, significantly diminished by the bottleneck through which the population has just passed. A classic calculation of population genetics suggests that exchange of genetic material at a rate roughly corresponding to transferring one individual from each subpopulation to another, in each generation, will be sufficient to prevent the local subpopulations diverging genetically ${ }^{1.6}$. It seems advisable to maintain such artificial manipulation of gene flow, at least until ferret populations are so widely distributed as effectively to constitute a large, contiguous population.

Not to be unrelievedly cheerful, this rescue mission cost about two million dollars up to 1986 , with the money coming both from government agencies and from the private sector ${ }^{1}$. Although this is a trifling sum compared with that spent on other scientific endeavours (how about sequencing the black-footed ferret genome; that should see them safe?), it is large by usual standards for this sort of endeavour. Conservation biology urgently needs funding at higher levels than it has heretofore received, or else Noah's Ark II is going to be rather empty.

Robert M. May is a Royal Society Research Professor at Imperial College London and at the Department of Zoology, University of Oxford, Oxford OX1 3PS, UK.

1. US Fish and Wildlife Service Black-footed Ferret Recovery Plan (US Fish and Wildlife Service, Denver, 1988).

2. Morkill, A.D. et al. in Endangered and Nongame Bird and Mammal Investigations. 47-58 (Wyoming Game and Fish Department, Cheyenne, 1987).

3. May, R.M. Nature 320, 13-14 (1986).

4. Thorne, E.T. et al. Conserv. Biol. 2, 41-49 (1988)

5. Groves, C.R. \& Clarke, T.W. Great Basin Natn. Mem. 8 , Groves, C.R. \& Cl
$150-159(1986)$

6. Ballou, J.D. \& Oakleaf, B. Demographic and Genetic Breed Recommendations for the Captive Populations of Blackfooted Ferrets (Int. Un. Conserv. Nature Natn. Resources Rep., Minneapolis, 1987).

\section{Maidenhead revisited}

LIKE all vertebrates, human beings have two independent gonads: ovaries in women, testicles in men. This doubling-up of important organs is typical of nature's shrewd redundant design; somebody who loses one of the pair can still function quite well on the other. Our gonads remain dormant throughout childhood, and spring into action together at adolescence. Later on in life, as their owner's chances of further successful parenthood begin to fade, they decline together as well.

Daedalus now plans to dodge this melancholy but universal fate. Suppose, he says, that one gonad of the pair could be protected from adolescent maturation by some sort of local implant to its blood supply, absorbing or neutralizing the hormonal stimuli. It would then remain dormant while its partner came to life. The individual thus treated would grow up quite normally, and could enjoy an active and vigorous sexual life. But when at last middle age or menopause began to threaten, he or she would have the implant removed. The longdormant second gonad would then blaze into action, resetting the biological clock right back to first youth.

Sadly, the precise hormonal triggering of puberty is still obscure. But DREADCO's biochemists, building on their recent search for a puberty-delaying hormonal antagonist, are confident of ultimately synthesizing the implant compound they already refer to as 'The Second Barrel'. Once perfected, it will revolutionize human life.

Firing the Second Barrel will have rapid and dramatic results. Adolescent vigour and sexual energy will blaze again in middle age. At first Daedalus had bizarre visions of fist-fights breaking out in Senior Common Rooms, of street gangs with names like Hell's Managers and Boot Boffins, of portly gentlemen in leather jackets chatting up giggling matrons on street corners while baffled teenagers looked on furiously at this invasion of their social niche. But this is too pessimistic. Second Barrellers will combine the vigour of youth with the wisdom and experience of age; they will handle their new powers with enviable grace and effectiveness. Their intellectual drive will also revive. A lifetime's knowledge, fanned anew by adolescent curiosity, vigour and alertness, should burst into fresh creative flame.

Women in particular will benefit from Second Barrel technology. Their implant will be more invasive but less noticeable than that for men. It will probably not extend fertility to an inconvenient age: the newly activated ovary will contain ova too old and decrepit to be viable. Far more effective and long-lasting than hormone replacement therapy, it will deliver in reality that enduring youthfulness that cosmetics only promise. 